\title{
DUAS CONCEPÇÕES DE REALISMO JURÍDICO: O PENSAMENTO DE OLIVER HOLMES E DE ALBERTO TORRES
}

Daniel Machado Gomes ${ }^{1}$ Maurício Pires Guedes ${ }^{2}$

Resumo: Diferentes formulações do realismo jurídico se caracterizam pela oposição ao formalismo e ao conceitualismo. Entre as teorias realistas se encontram as propostas de Oliver Holmes e de Alberto Torres que são o objeto do presente trabalho cuja finalidade é contrastar a perspectiva destes autores e investigar suas contribuições para o Direito nos dias de hoje. Na elaboração deste artigo foi empregado o método dedutivo e comparativo, valendo-se da pesquisa bibliográfica. $\mathrm{O}$ trabalho conclui que estudo do realismo jurídico norte-americano e brasileiro colabora para a teoria constitucional atual cujo maior desafio é evitar soluções artificiais e inadequadas.

Palavras-chave: antiformalismo; antiliberalismo; teoria realista; constitucionalismo; poder judiciário.

\section{TWO CONCEPTIONS OF LEGAL REALISM THE THOUGHT OF OLIVER HOLMES AND ALBERTO TORRES}

\begin{abstract}
Different formulations of legal realism are characterized by opposition to formalism and conceptualism. Among the realistic theories are the proposals of Oliver Holmes and Alberto Torres, which are the object of the present work whose purpose is to contrast the perspective of these authors and investigate their contributions to the Law in the present day. In the elaboration of this article the deductive and comparative method was employed using bibliographical research. The paper concludes that a study of American and Brazilian legal realism contributes to the current constitutional theory whose greatest challenge is to avoid artificial and inadequate solutions.
\end{abstract}

Keywords: antiformalism; antiliberalism; realistic theory; constitutionalism; judicial power

\section{INTRODUÇÃO}

Ao enxergar o direito como fato, o realismo jurídico se distancia tanto das perspectivas conceitualistas quanto das visões formalistas. Neste sentido, o realismo encontra-se comprometido com soluções jurídicas adequadas para sociedades concretas. A principal

\footnotetext{
${ }^{1}$ Professor do Programa de Pós-Graduação em Direito da Universidade Católica de Petrópolis. Professor das Faculdades Integradas Hélio Alonso. Doutor em Filosofia pelo IFCS, UFRJ. Mestre em Ciências JurídicoCivilísticas pela Universidade de Coimbra, Portugal. E-mail: daniel.machado@ucp.br.

${ }_{2}^{2}$ Professor da Graduação da Universidade Católica de Petrópolis. Doutorando em Direito pela Universidade Veiga de Almeida. Mestre em Direito pela Universidade Gama Filho. E-mail: mauricio.guedes@ucp.br.
}

Revista de Teorias do Direito e Realismo Jurídico | e-ISSN: 2525-9601 | Porto Alegre | v. 4 | n. 2 | p. $38-53$ | Jul/Dez. 2018 
questão do presente trabalho é expor convergências e divergências entre duas formulações da teoria realista: a versão do norte-americano Oliver Holmes e a proposta do brasileiro Alberto Torres. O texto tem o objetivo de apontar as premissas e as construções teóricas que sustentam o realismo na concepção de Holmes e de Torres, contrastando a perspectiva dos autores e indicando a contribuição da teoria realista para o direito atual. $\mathrm{O}$ estudo se justifica pela relevância do realismo na Teoria do Direito e no pensamento constitucional, fato que se evidencia na influência das ideias de Holmes e de Torres respectivamente nos EUA e no Brasil. O método empregado na elaboração deste artigo foi dedutivo e comparativo, o artigo se valeu da pesquisa bibliográfica com a utilização livros e artigos de periódicos.

O texto que segue está divido em três partes, na primeira seção serão analisadas as ideias de Oliver Holmes e sua proposta de uma teoria realista que se opõe ao laissez-faire da Corte e ao conceitualismo jurídico, o que também pode ser sentido na obra de outros autores do realismo jurídico norte-americano, movimento que se inicia no final do século XIX e que atinge o seu auge no período entre guerras na primeira metade do século XX. Holmes teve grande influência no pensamento constitucional estadunidense, notadamente a partir das subjacentes relações que suas acepções sobre o direito trazem para tradição jurídica norteamericana consolidada no final do século XIX.

Na segunda parte do artigo será apresentada a contribuição Alberto Torres para as ideias jurídicas no Brasil que se deu pela formulação de um realismo baseado no compromisso com soluções nacionais, criticando os transplantes europeus e americanos para o direito brasileiro. Torres buscou soluções baseadas no conhecimento da cultura e das gentes do Brasil, daí sua inegável importância para a nossa história constitucional e para a adequada compreensão da realidade jurídica nacional. O trabalho irá demonstrar o caráter inovador do projeto de Alberto Torres que configura um realismo jurídico tipicamente brasileiro. Mais ainda, em igual e maior sentido, com o estudo do realismo jurídico de Alberto Torres quer-se apontar que o realismo jurídico foi um movimento de reação ao formalismo que surge no Brasil no início do século XX, revelando-se fundamental para o desenvolvimento e consolidação do Estado nacional contemporâneo.

A última parte do texto apresentará contrastes e consonâncias entre o realismo jurídico de Oliver Holmes e de Alberto Torres, traçando um paralelo do papel precursor de Holmes para o movimento nos EUA com o pioneirismo de Torres no Brasil. Por fim, o estudo demonstrará porque o realismo jurídico no Brasil e nos EUA foi muito além do clássico 


\section{DUAS CONCEPÇÕES DE REALISMO JURÍDICO: O PENSAMENTO DE OLIVER HOLMES E DE ALBERTO TORRES}

constitucionalismo que surge ao final do século XIX, já que forneceu novos instrumentos para aplicação das normas jurídicas e marca a crítica do formalismo jurídico dentro dos estudos de Teoria do Direito até os dias de hoje.

\section{OLIVER HOLMES E O REALISMO JURÍDICO NORTE-AMERICANO}

Para a caracterização do Realismo Jurídico Norte-Americano, é necessário destacar a importância de Oliver Wendell Holmes Jr., juiz da Suprema Corte estadunidense entre 1902 a 1932, e sua crítica ao idealismo e ao estático formalismo jurídico. O pensamento de Holmes caracteriza-se pela contundente crítica à objetividade e à formalidade que circundavam o processo de aplicação do direito no paradigma até então existente, de modo que seu mérito, resumidamente, foi retirar o juiz da passiva posição colocada pela teoria jurídica clássica para incluí-lo, ativamente, no papel soberanamente a ele confiado para aplicar as normas jurídicas a partir de elementos sociais que circundam o caso concreto.

Interessante notar que a partir de Holmes a própria concepção de justiça passa por uma reviravolta. Não só no que tange a seu papel, mas também quanto a sua finalidade conforme pode ser constatado desde o início de seu mais importante livro, "The common law":

A vida do direito não foi lógica; foi experiência. As necessidades da época, a
moral dominante e as teorias políticas, as intuições políticas, confessadas ou
inconscientes, até mesmo os preconceitos que os juízes partilham com seus
concidadãos, representaram papel muito mais importante que o silogismo na
determinação das regras pelas quais seriam governados os homens. [...] A
substância do direito em qualquer momento corresponde, aproximadamente,
dentro de sua esfera, àquilo que se acredita ser conveniente; mas sua forma e
maquinismo, assim como o grau em que pode produzir os resultados
desejados, dependem muito do seu passado. (HOLMES Apud RODRIGUES,
1992, p.103)

Oliver Holmes se contrapõe ao formalismo jurídico, defendendo uma flexibilidade na interpretação constitucional, por entender que as gerações presentes não estão presas ao passado. Ele insistia em parâmetros de decisão puramente práticos que não poderiam ser apreendidos pela gramática ou pela lógica. Para Holmes, proposições gerais não decidem casos concretos, o direito não é lógica, é experiência.

Holmes desconfiava do tradicionalismo como justificativa da autoridade, tendo liderado uma revolta contra o formalismo jurídico e atacado o conceitualismo de Harvard. Seu

Revista de Teorias do Direito e Realismo Jurídico | e-ISSN: 2525-9601 | Porto Alegre | v. 4 | n. 2 |

p. $38-53$ | Jul/Dez. 2018 
pragmatismo e ceticismo persistem ainda nos dias de hoje no pensamento jurídico norteamericano.

De fato, o culto à lei enquanto fonte primordial do direito acabou revelando-se obstáculo intransponível para a transformação dos fatos e ideias da sociedade, tanto que este novo período ficou marcado, em maior ou menor escala, pela reiterada busca de superação das bases e alicerces tradicionalistas até então vigentes.

Nos Estados Unidos da América, durante as décadas de 20 e 30 do século XX, é possível verificar uma grande influência do realismo jurídico, pois se entendia que o direito, enquanto fenômeno social, deveria estar na realidade empírica permeando a resolução de casos concretos. Este posicionamento ecoou significativamente no desenvolvimento do pensamento político ocidental posterior.

Impondo à vida social questões políticas que até então lhe eram renegadas, esclarece Lêda Boechat Rodrigues a exata relevância da mudança efetivada por este movimento na história jurídica estadunidense:

Através de amplíssima construction constitucional, baseada sobretudo na
interpretação da $14^{\text {a }}$ Emenda, transformou-se a Corte em árbitro não só da
vida jurídica, mas das próprias diretrizes políticas nacionais, ao dar soluçãao
judicial a questões "não só morfológica como substancialmente políticas",
segundo observação de Pontes de Miranda. Colocando-se na posição de
declaradores de um direito natural acima da própria Constituição, os juízes
daquele tribunal passaram a julgar da superconstitucionalidade das leis, em
vez de limitar-se a dizer de sua simples constitucionalidade ou da
competência do legislador, sob o império da Constituição, para adotar tal ou
qual medida. As leis não eram mais declaradas inválidas, em sua maioria,
por incompatibilidade com os textos da Constituição e os processos por ela
estabelecidos, mas por incompatibilidade com os grandes princípios
superiores à mesma. O principal resultado desse controle da
superconstitucionalidade das leis pela Corte Suprema, nessa fase, foi
emancipá-la do documento constitucional, pois ela não se limitava a aplicar
regras legais estritas às questões constitucionais, mas agia como um
departamento político com poderes de governo. (RODRIGUES, 1992,
p.100)

Relevante observar, nesse passo, que o realismo jurídico estadunidense não constitui mera recepção da clássica filosofia do direito natural, abandonada e desacreditada pelo período formalista anterior. Ao contrário, embora ambos os movimentos tenham a justiça como elemento comum, a filosofia do direito natural buscava encontrar o "direito justo" fora 


\section{DUAS CONCEPÇÕES DE REALISMO JURÍDICO: O PENSAMENTO DE OLIVER HOLMES E DE ALBERTO TORRES}

do "direito positivo" (e este elemento a caracterizou), enquanto para o realismo jurídico o "direito" e a "justiça" deveriam ser inferidos e firmados dentro do próprio "direito positivo".

Nesse sentido é recorrente a análise que Benjamim Cardozo, outro relevante adepto deste movimento, faz do "direito" a partir deste viés social conferido a norma, demonstrando inclusive a plena consciência da profunda alteração que este movimento jurídico quis perpetrar. Cardozo esclarece que:

É verdade que hoje em dia, em todas as áreas do Direito, o valor social de uma norma tornou-se um critério de poder e importância crescentes. Essa verdade é proferida com veemência, aos juristas deste país, nos escritos de Dean Pound. "O avanço mais significativo na moderna ciência do Direito talvez seja a mudança da atitude analítica para o funcional". "A ênfase deslocou-se do conteúdo do preceito e da existência do remédio para o efeito do preceito em ação e a disponibilidade e eficiência do remédio para alcançar os fins para os quais se formulou o preceito." Os juristas estrangeiros pensam da mesma maneira: "A função judicial como um todo" dia Gmelin, "foi [...] alterada. A vontade do Estado, expressa na decisão e no julgamento, é chegar a uma determinação justa por meio do senso de justiça subjetivo inerente ao juiz, orientado por uma ponderação efetiva dos interesses das partes à luz das opiniões em geral prevalecentes entre a comunidade no que diz respeito a transações como aquelas que estão em questão. Em quaisquer circunstâncias, a determinação deve estar em harmonia com as exigências da boa-fé nas relações comerciais e as necessidades da vida prática, a menos que uma lei escrita positiva o impeça; e, ao se ponderarem interesses conflitantes, deve-se contribuir para que o interesse mais bem fundamentado na razão e o mais digno de proteção alcance vitória. (CARDOZO, 2004, 52-53)

Se, por um lado, a disposição expressa da lei deveria ser observada pelo magistrado independente da hipótese colocada sob julgamento, fruto de raciocínio anterior, geral e abstrato sobre determinada situação cujas bases estruturantes não poderiam vir a ser modificadas, por outro, não se admitirá relegar o direito a uma função que não corresponda ao seu proeminente papel dentro do arcabouço político e social, sendo importante destacar, uma vez mais, o reconhecimento do efetivo exercício de parcela da soberania do Estado pelo Poder Judiciário na aplicação da norma jurídica aos casos concretos.

A autocontenção judicial parte do pressuposto de que o legislador - e, portanto, em última instância, a própria legislação - constituiria apenas o primeiro responsável por adequar a norma à realidade, de modo que seria atribuição do Poder Judiciário, a partir do caso concreto e enquanto detentor de parcela da soberania estatal, moldá-la aos fins sociais a ela subjacentes.

Revista de Teorias do Direito e Realismo Jurídico | e-ISSN: 2525-9601 | Porto Alegre | v. 4 | n. 2 | p. $38-53$ | Jul/Dez. 2018 
Nesse sentido conclui Cardozo, com a síntese que lhe é peculiar, ao tratar da relevância do papel do magistrado para o sistema democrático desse período:

É insignificante o poder de inovação de qualquer juiz quando comparado à magnitude e à pressão das normas que o restringem de todos os lados. Até certo ponto, porém, ele deve inovar, pois novas condições pedem novas normas. O método da sociologia exige apenas que, dentro desse restrito espaço de escolha, o juiz busque a justiça social. Houve etapas na história do Direito em que se fez necessário um método menos psicológico. Os velhos critérios quantitativos de verdade atendiam ás necessidades de sua época. Mas isso foi há muito tempo. O pensamento jurídico moderno, voltando-se para si mesmo, submetendo o processo judicial à análise introspectiva, pode nos ter dado uma terminologia e uma ênfase até então desconhecidas. $\mathrm{Na}$ verdade, porém, seu método não é novo. É o método dos grandes juízes dos tribunais de equidade que, sem sacrificar a uniformidade e a certeza, construíram o sistema de equidade recorrendo constantemente aos ensinamentos da razão e das consciências justas. É o método pelo qual ao common law se revitalizou nas mãos de seus grandes mestres - o método de Mansfield, Marshall, Kent e Holmes. (CARDOZO, 2004, p.100-101)

Por todo o exposto acima, é possível afirmar que há um importante legado para a Teoria do Direito deixado pelo realismo jurídico formulado por Oliver Holmes, especialmente, em relação à ruptura com o modelo tradicionalista e à crença nos Tribunais como definidores do direito.

\section{O REALISMO JURÍDICO BRASILEIRO}

A partir de uma visão antiliberal de que somente o Estado forte e seguro poderia garantir a democracia brasileira, ficaria marcado no pensamento de Alberto Torres sua preocupação com as intervenções políticas e sociais necessárias para a efetiva consolidação da unidade nacional. Relevante destacar, nesse sentido, que esta questão surge desde o prefácio de sua obra mais importante, A Organização Nacional, se tornando a tônica do debate por ele realizado:

A nossa história mostra que somos capazes de esforços para reformar. [...] Erros políticos e surpresas internacionais à parte, o nosso país goza da fortuna privilegiada de ter problemas, sem ter dificuldades, possuindo o povo de coração mais brando e de mais sensato espírito, talvez, no mundo inteiro; só o não governa quem o não sabe, ou não o quer, governar; e todos os seus problemas se resumem neste objetivo: formar, construir e desenvolver a Nação, que é a nossa gente de hoje e a sua prole, a gente das nossas raças e a dos que vierem, cordial e fraternalmente, conviver conosco: a verdadeira, a única Pátria, para corações sinceros e para espíritos serenos.

Revista de Teorias do Direito e Realismo Jurídico | e-ISSN: 2525-9601 | Porto Alegre | v. 4 | n. 2 |

p. $38-53$ | Jul/Dez. 2018 


\section{DUAS CONCEPÇÕES DE REALISMO JURÍDICO: O PENSAMENTO DE OLIVER HOLMES E DE ALBERTO TORRES}

A desorganização política destrói uma Nação mais do que as guerras. [...] Será preciso, depois, sermos corajosos, conscientes e perseverantes, para assentar, consolidar e desenvolver a organização. "Os brasileiros — escrevi eu há longos anos - provaram já que sabem ser soldados da República; precisam agora provar que sabem também ser cidadãos". "O Brasil, escrevio, também, mais ou menos pelo mesmo tempo, tem estado, até hoje, ao serviço das formas de governo e das doutrinas que tem adotado: cumpre que a República passe, por sua vez, a servi-lo". (TORRES, 1982, p.57-58)

De fato, interessante observar que Alberto Torres integra um grupo de republicanos brasileiros que, no início do século $\mathrm{XX}$, não vislumbra na política liberal da primeira república o alicerce necessário para o desenvolvimento da sociedade. O estudo da sociedade brasileira e suas peculiaridades, consignadas a partir de uma visão crítica da história e de nosso desenvolvimento social, servirão de pano de fundo para a análise que ele buscará realizar.

Sua obra ainda hoje é reconhecida como referência para o pensamento nacionalista no Brasil, fruto da incipiente compreensão da posição periférica que Alberto Torres conscientemente insere nosso Estado, cuja ameaça, representada pela equivocada interpretação de doutrinas estrangeiras, decorreria da não adequação das instituições políticas criadas pela legislação nacional à realidade de nosso povo.

De acordo com Alberto Torres, a longa história desde o descobrimento em 1500 não coincidia com a recente história política de nosso país, de modo que, em sua visão, o nacionalismo brasileiro estaria dando os primeiros passos de sua formação apenas no início do século XX.

O desenvolvimento de toda a potencialidade da nação, "esboço da humanidade futura" como ele mesmo definia (1982, p.135), dependeria da tomada de consciência pelo nosso povo das condições peculiares de nossa terra, de nossa sociedade e do meio ao qual nós estamos inseridos. Nesse sentido ele argumenta:

A preocupação da Moral e a ação exclusiva da Moral não fazem Moral, porque a Moral é uma abstração, a abstração não se realiza senão retomando seu lugar na síntese concreta da vida: do que resulta que a anarquia moral de uma sociedade desorganizada não é sinal de amoralidade ou de imoraldiade; e que os estados de anarquia moral não se corrigem por força de sanções morais, ou por ação puramente moral. Nenhum povo tem melhores estímulos morais e mais alta capacidade moral que o nosso. Entre poucos, a vida pública terá chegado, entretanto, ao mesmo estado de aparente licença e desmoralização. É um desequilíbrio funcional do critério moral - resultado da desagregação social. Nestes casos, as reações do "moralismo" agem como 
irritantes ou como enervantes; provocam situações de terror, ou situações de torpor. A nossa reação deve basear-se nestes dados: confiança inteira em nossa indisputável moralidade, a consciência da causa real da nossa apatia, que está na ignorância do nosso meio e de nós mesmos, produzindo, por conseqüência lógica, a extraordinária leviandade do nosso espírito. A presente geração brasileira assiste à gestação da nossa nacionalidade. (TORRES, 1982, p.45)

Deve ainda ser destacada a preocupação de Alberto Torres com a falta de vontade política da elite brasileira para a resolução dos problemas nacionais, fruto da equivocada preocupação com questões filosóficas e jurídicas estudadas a partir de teorias estrangeiras que distanciavam nosso Estado dos problemas próprios de nossa terra e de uma visão pragmática das questões que nossa sociedade demandava:

O regime de opinião depende de um certo grau de cultura e de um grau maior de civismo. Possuímos ilustração em escala mais elevada do que civilização. Ao passo que o nosso povo conta uma imensa massa de analfabetos e, sem incluir os indígenas, de indivíduos ainda em estado, material e moral, de selvageria, o número dos intelectuais é avultado e notável a elevação de seu preparo. Mas, no intelectualismo, a forma erudita e ornamental predomina sobre a forma intensa e raciocinante. Saber muito e dizer bem é o ideal cultivado pela maioria dos que estudam: poucos se preocupam com o formar uma filosofia prática e ter opinião sobre os problemas; quase todos afetam, sobre as coisas da política e da vida pública, a indiferença característica das culturas em decadência. Os que não usam da cultura como simples arma de combate pessoal, mantêm-se no terreno das fórmulas vagas e das teorias abstratas, onde não correm risco de perder simpatias e popularidade. Há um propósito de abstenção visível, no meio intelectual, que deveria exercer a iniciativa da discussão e dar impulso às correntes de idéias. Os intelectuais brasileiros consideram o preparo que possuem um meio de êxito pessoal, sem o ligar a nenhum dever, a nenhuma responsabilidade de ação e direção social. (TORRES, 1982, p.90-91)

Nesse sentido, e em maior escala que grande parte dos defensores desta visão de Estado, não por outro motivo Alberto Torres foi um dos maiores críticos da implantação de institutos e instituições estrangeiras em solo nacional sem as devidas e necessárias adaptações a nossa peculiar organização, o que, em sua visão, acabaria importando verdadeira subversão do próprio sistema político.

Deve ser destacado que esta era a realidade a qual Alberto Torres estava constitucionalmente inserido, na medida em que a transplantação de diversos princípios norteamericanos para contexto jurídico nacional em 1891 desconsiderou o sistema pós-monárquico 


\section{DUAS CONCEPÇÕES DE REALISMO JURÍDICO: O PENSAMENTO DE OLIVER HOLMES E DE ALBERTO TORRES}

vigente e as peculiaridades sociais e econômicas em nossa país, gerando, na prática, a deturpação na aplicação destes institutos.

A autonomia dos estados-membros, caracterizada pela auto-organização, pelo autogoverno e pela autoadministração, significou pragmaticamente a ruptura da dependência local e regional com o centro de poder político, o que propiciou o crescimento de forças até então não tão relevantes no cenário social brasileiro.

Exatamente neste contexto de exclusão da maioria do processo de participação política, aliado à efetiva criação de mecanismos para a manutenção no poder do grupo dominante, é que surgirá o grande obstáculo que o nacionalismo de Alberto Torres buscará superar, cujas bases, sob o ponto de vista estritamente jurídico, implicará na necessidade de alteração estruturante da legislação então vigente.

A revisão da Constituição, nesse contexto, exsurge como pedra angular da política que Alberto Torres almeja ver implantada no Brasil, e sem a qual, em sua opinião, continuariam a subsistir todos aqueles interesses que, vigorando desde início do período republicano, não levaram nosso país ao progresso e ao desenvolvimento próprio das sociedades democráticas.

E nesse hiato entre a realidade constitucional e a realidade social que Alberto Torres defenderá os conceitos e as bases de uma doutrina realista do direito no âmbito nacional a partir da ideia de que a nação brasileira deveria ser criada pelo Estado a fim criar vínculos capazes de consolidar o país enquanto nação. Vale ressaltar que os pressupostos jurídicos do pensamento de Alberto Torres encontram um certo paralelo com as críticas ao direito norteamericano apresentadas por Oliver Wendell Holmes Jr, conforme veremos neste trabalho.

A visão jurídica de Torres revelava-se adequada ao sentido que ele adota para a unidade nacional, tendo por objeto a consolidação do Estado enquanto detentor supremo da soberania. Ele concedia à Constituição largo alcance para, longe das imperfeições e incoerências decorrentes da desmedida importação de princípios estrangeiros, moldar seu texto a prática e a realidade nacional.

O liberalismo defendido no período anterior revelava-se na visão de Alberto Torres mero instrumento de arbítrio à disposição daqueles que buscavam interpretar as normas jurídicas de acordo com sua própria conveniência, acabando por restringir, em sua visão, o que havia de mais importante em sua essência, a transformação da sociedade.

Justamente ao afirmar a necessidade de atualização conceitual como único método apto e idôneo para garantir às leis o legítimo substrato político, social e organizacional da 
sociedade brasileira, defenderá Alberto Torres as bases do pragmatismo, imprescindível instrumento nesse contexto para a adequada resolução de conflitos concretamente analisados.

Nesse sentido, por exemplo, recomendou Alberto Torres a inclusão de dispositivo específico que deveria esclarecer o papel político e o fim prático das normas jurídicas em geral, sugerindo que esta questão passasse a integrar o próprio texto constitucional.

Inequívoco traço pragmático próprio das doutrinas realistas, propôs Alberto Torres a inclusão do seguinte artigo em nossa Carta Magna, em que ressalta teleologicamente a necessidade de que as normas jurídicas promovessem os fins da sociedade e da vida individual em nosso Estado:

Art. $81 \mathrm{Na}$ interpretação da Constituição e das leis devem os Juizes, legisladores e todos aqueles a quem competir a sua aplicação, ter em vista os seguintes princípios, de preferência a outras regras jurídicas de interpretação: I. A Constituição é uma lei política, de fins práticos, fundada em objetos sociais concretos, e destinada principalmente a manter ligados, harmônica e organicamente, os interesses gerais e permanentes do país;

II. A base de sua interpretação é o fim prático e social que seu conjunto e seus princípios se destinam a realizar;

III. Nem o sentido literal do texto, nem a fonte, origem, escola, ou tradição doutrinária a que estiver ligado, servirá de argumento a qualquer interpretação contrária a seu destino prática e seu fim social;

IV. Por elemento histórico da interpretação deve entender-se, não somente, nem principalmente, os debates, pareceres, discursos legislativos e mais atos preparatórios da elaboração da lei, mas, sobretudo, a razão de legislar e os interesses, relações e fatos, inspiradores dos princípios legislativos, e seus fins permanentes e gerais;

V. Sendo objeto da Constituição e das leis promover os fins da sociedade e da vida individual, seus princípios devem ser entendidos no sentido mais favorável a tais fins: ao desenvolvimento e progresso da sociedade e ao interesse e prosperidade dos indivíduos;

VI. O elemento prático da interpretação deve ser entendido com relação ao bem-estar geral e permanente da sociedade e do indivíduo, ao desenvolvimento e sucessão progressiva dos fatos e fenômenos sociais e jurídicos, e jamais aos acidentes, fatos isolados e interesses parciais e momentâneos.

Parágrafo único. Na elaboração das Leis, deverão os legisladores ter, igualmente, em vista os princípios deste artigo, na parte que lhe for aplicável. (TORRES, 1982, p. 322)

A evolução da sociedade e de seus paradigmas permeará expressiva parte da obra de Alberto Torres, funcionando como fio condutor que norteará a interpretação da Constituição 


\section{DUAS CONCEPÇÕES DE REALISMO JURÍDICO: O PENSAMENTO DE OLIVER HOLMES E DE ALBERTO TORRES}

pelo operador do direito e que terá por finalidade, de fato, colocar o Estado na primazia da construção da nação brasileira.

Ao apresentar e fundamentar a proposta de alteração legislativa da Constituição, defenderá Alberto Torres que a aplicação da lei ao caso concreto deveria corresponder muito mais aos fatos ocorridos do que ao direito teoricamente pensado. Trata-se de uma base comum às doutrinas realistas que argumentavam que somente com esta posição seria possível resguardar adequadamente o verdadeiro conteúdo das normas jurídicas. Nesse sentido relevante passagem de sua obra:

Entre nós, a redação da Constituição e a interpretação constitucional, obedecendo ao critério verbal e analítico, que herdamos de nossos antepassados e dos primeiros educadores de nosso espírito, fazem de cada disposição particular um princípio isolado, forte e eficiente, contra o conjunto expresso da constituição, os princípios implícitos em suas cláusulas e as ideias que, precedendo logicamente as razões das disposições expressas e dos princípios implícitos, e dominando-as necessariamente, formam a essência virtual - não só o espírito, no sentido comum da linguagem jurídica - mas a própria força motora, ativa e vital, do código da vida de um povo. (TORRES, 1982, p. 215)

A relevância da questão social trazida por Alberto Torres permeou igualmente a ideia de direito e de justiça na mesma linha defendida pela doutrina realista vista anteriormente, de modo que a aplicação da norma jurídica ao caso concreto também deveria ter como parâmetro à conveniência do interesse público e os imperativos de ordem social.

Do mesmo modo, parte da crítica de Alberto Torres pressupõe, no campo do direito, a superação de antigos paradigmas que preconizavam a interpretação literal da norma jurídica, fazendo prevalecer, a partir do caso concreto, os métodos teleológico, sistemático e históricoevolutivo:

O espírito dos nossos legisladores, juizes e políticos, educado nos métodos de análise jurídica - critério quase exclusivo, na elaboração e interpretação do Direito Privado, e único método praticado nas academias e no foro, sobre textos suscetíveis de exame e de aplicação isolada ou, pelo menos, parcial não se afeiçoou ainda ao caráter dessa lei superior, norma de uma personalidade coletiva, que, exatamente porque contém o Direito Público de toda a nação, em globo, forma um Direito complexo, geral, cujo objeto é corporificado no território e na sociedade, abrangendo-os como num sistema de concentração e de harmonia, onde cada princípio especial é como que o portador, para os casos particulares, de seus pensamentos mais vastos, não atingindo o indivíduo senão por efeito reflexo e por compreensão e onde não

Revista de Teorias do Direito e Realismo Jurídico | e-ISSN: 2525-9601 | Porto Alegre | v. 4 | n. 2 | p. $38-53$ | Jul/Dez. 2018 
se separa o todo, em artigos e parágrafos, senão para comunicar aos vários órgãos públicos a própria vida da sociedade: uma lei global, em suma, firmada sobre princípios básicos, gerais e fundamentais, que, se lhe não incutem propriamente unidade, dão-lhe alcance universal sobre todas as partes. A palavra "constituição", envolvendo a idéia de que esta lei é a expressão da vida nacional, tem o valor de seu sentido fisiológico: é uma predicação política feita para assinalar que é uma lei adaptada à realidade social, obedecendo a fins práticos, não só originariamente inspirada em certa ordem de objetos gerais e permanentes, mas ordinariamente dominada pelo escopo de sua aplicação ao desenvolvimento evolutivo da sociedade. A política é o laço que domina o corpo da constituição e liga suas disposições entre si e sua inteligência aos movimentos da sociedade, do povo e dos fatos. Daí a supremacia, na interpretação, deste amplo e elevado sentido, sobre a inteligência expressa, isolada e lateral da lei. (TORRES, 1982, p. 215-216)

Sob outra perspectiva, interessante notar que a Constituição pensada por Alberto Torres pressupõe a sua efetiva aplicabilidade prática, que para além de norma jurídica em sentido formal, deve representar o verdadeiro espírito do povo brasileiro:

A Constituição, como lei prática, não pode ser uma lei formal: é um verdadeiro roteiro político; uma síntese, não só dos métodos, processos e instrumentos, necessários ao progresso nacional, senão, também, de seus grandes fins e objetivos ditados pela natureza de sua terra e de seu povo. Formulada neste espírito, ela evita, por um lado, o arbítrio, e habilita o poder a realizar os encargos do governo. Cumpre gravar firmemente nos espíritos esta ideia de que a lei constitucional é uma lei nacional - a fonte de todas as leis nacionais e a lei nacional suprema - onde os problemas do presente e os do futuro devem estar indicados e fixado o índice de suas soluções. (TORRES, 1982, p. 249)

Sob o ponto de vista estruturante, por exemplo, Alberto Torres defende a modificação das bases do federalismo brasileiro, que deveria estar de acordo com a nossa história nacional. A mudança do nome do Estado brasileiro de "Estados Unidos do Brasil" para "República Federativa do Brasil" não se apresenta para Alberto Torres como mera alteração da referida denominação em sentido teórico, mas no reconhecimento da ausência de capacidade de determinados "estados-membros" - que passariam a ser denominados "províncias autônomas" controladas pela "soberania política da União" -, em exercer as respectivas funções constitucionais.

A cláusula "e a soberania política da União", que se acrescenta ao mesmo número, destina-se a assinalar, por meio duma fórmula de alcance geral, que, órgão da Nação e do Povo, investido da guarda e da defesa dos interesses gerais e permanentes da terra brasileira e de seus habitantes, e incumbido de zelar, o presente, pela sociedade e pelos indivíduos, e, no futuro, pela

Revista de Teorias do Direito e Realismo Jurídico | e-ISSN: 2525-9601 | Porto Alegre | v. 4 | n. 2 | p. $38-53$ | Jul/Dez. 2018 


\section{DUAS CONCEPÇÕES DE REALISMO JURÍDICO: O PENSAMENTO DE OLIVER HOLMES E DE ALBERTO TORRES}

conservação e pelo melhoramento do território, de sua produtividade e de sua riqueza, pela vida e progresso das raças e da nacionalidade, não pode a União reconhecer, nos agrupamentos particulares do país, interesses, fins e objetivos, contrários a seus desígnios superiores e a seu solene e insubrogável mandato. Sua "soberania" não é limitada pela autonomia circunscricional das províncias e dos municípios, mas pelos interesses do indivíduo, da sociedade, da nação e da espécie. (TORRES, 1982, p.221)

Ainda dentro da organização estatal delineada por Alberto Torres, por outro bordo, haveria a necessidade da criação de um quarto poder, o poder coordenador, com a finalidade de fortalecer, a partir de seus diferentes órgãos e representatividades, a adequada prática dos atos governamentais:

A criação do Poder Coordenador coroa, por fim, estas disposições tendentes, todas, a fortalecer a ação governamental, a ligar solidariamente as instituições do país e a estabelecer a continuidade na prossecução dos ideais nacionais, a "realizar", em suma, a soberania da lei, a democracia, a república, a autonomia e a federação - com um órgão, cuja função será concatenar todos os aparelhos do sistema político, como mandatário de toda a Nação - da Nação de hoje, como da Nação de amanhã - perante seus delegados. (TORRES, 1982, p.252)

Pioneiro, este estudo iniciado por Alberto Torres foi seguido por uma série de autores que buscaram compreender a sociedade brasileira a partir da análise de nossas peculiares questões sociais e políticas, sendo oportuno destacar, dentre outros, a figura de Oliveira Vianna, adepto do realismo e grande entusiasta deste movimento no Brasil:

Torres e eu, o que um e outro fizemos em relação ao conhecimento científico da nossa evolução e formação social, do ponto de vista especialmente da evolução das instituições políticas e da estrutura do Estado consistiu, aqui, nesta novidade metodológica: considerar os problemas do Estado ou, melhor, os problemas políticos e constitucionais do Brasil, não apenas simples problemas de especulação doutrinária ou filosófica como então se fazia e como era o método de Rui; mas como problemas objetivos, vinculados à realidade cultural do povo e, conseqüentemente, como problemas de comportamento do homem brasileiro na sociedade brasileira de "comportamento", no estrito e técnico sentido que a esta expressão the dão os sociologistas americanos (como, por exemplo, Ralph Linton e Donald Pierson, em livros que estão hoje, em nosso país, nas mãos de todos os estudiosos das ciências sociais). (VIANNA, 1999, p.399-400)

Revista de Teorias do Direito e Realismo Jurídico | e-ISSN: 2525-9601 | Porto Alegre | v. 4 | n. 2 | p. $38-53$ | Jul/Dez. 2018 
O que se quer demonstrar, de tudo o que foi exposto, é que Alberto Torres pressupunha a aplicação pragmática da norma jurídica a partir das circunstâncias que permeavam o caso concreto, inaugurando uma nova forma de pensar o estudo do direito, notadamente o direito constitucional, cujas implicações podem ser encontradas nos diversos espectros políticos e sociais do direito contemporâneo.

\section{ENTRE CONTRASTE E CONSONÂNCIA}

Conforme visto, o movimento antiformalista nos Estados Unidos da América se concentra no fato de que a aplicação da norma jurídica ao caso concreto constitui parcela do exercício da soberania nacional. No Brasil o surgimento da visão pragmática de Alberto Torres reconheceu que a ausência de conhecimento adequado de nossa realidade importa no esvaziamento de nossa soberania. Na prática, os dois discursos trazem luzes e instrumentos que marcam e modificam o estudo da Teoria do Direito em cada um desses sistemas.

Assim, no início do século XX, no espaço existente entre a realidade constitucional e a realidade social floresceram nos Estados Unidos da América e no Brasil, movimentos que buscaram a consolidação da própria sociedade como centro da preocupação do Direito. Neste sentido, cada qual a partir de seu respectivo interesse social, os realismos jurídicos de Holmes e Torres defenderam questões referentes à justiça e à equidade que romperam, aqui e lá, com os paradigmas formalistas então vigentes.

Será dentro destes movimentos que a jurisdição passará a servir aos propósitos de uma nova sociedade preparando-se para o início do terceiro milênio, cuja percepção do indivíduo, enquanto sujeito de direito, propiciará o surgimento das diversas teorias contemporâneas existentes. A partir de suas matrizes ideológicas e sua preocupação com a sociedade em geral, em especial com a ordem social que permeará a atuação estatal, estes movimentos acabaram por preencher perfeitamente os valores e paradigmas da sociedade brasileira, especialmente aquela que se desenvolve após a morte de Alberto Torres

Logo, vistos os limites que circunscrevem o constitucionalismo norte-americano das primeiras décadas do século XX, evidenciam-se semelhanças entre o realismo de Holmes e o realismo jurídico proposto por Alberto Torres. Entretanto, as bases jurídicas lá e aqui são muito distintas, de maneira que, em cada um dos países, os objetivos do movimento foram bastante diferentes. Nos EUA o realismo é uma sobretudo uma oposição ao pensamento 


\section{DUAS CONCEPÇÕES DE REALISMO JURÍDICO: O PENSAMENTO DE OLIVER HOLMES E DE ALBERTO TORRES}

jurídico clássico caracterizado pelo conceitualismo, pela neutralidade e pelo laissez-faire. No Brasil o realismo proposto por Alberto Torres é essencialmente uma crítica às ideias fora de lugar, aos transplantes europeus e americanos dissonantes com a sociedade brasileira. Com isso, Torres propunha soluções mais adequadas à realidade nacional a partir de uma análise profunda de nossa população e cultura.

Em que pese o esforço de Alberto Torres para se opor a soluções estrangeiras no âmbito jurídico, suas ideias se aproximam de algumas críticas apontadas por Oliver Wendell Holmes Junior, precursor do Realismo Jurídico Norte-Americano, movimento que se desenvolveu a partir do fim do século XIX e cujo auge foi alcançado no século XX, no período entre guerras. Guardadas as devidas proporções e particularidades, no Brasil, Alberto Torres exerceu um papel precursor na cultura jurídica semelhante ao que representou Oliver Wendell Holmes Junior representou nos Estados Unidos da América.

\section{CONCLUSÃO}

De tudo o que foi exposto, o que se observa, de fato, é que extrapolando o mero limite das questões legais, os dois movimentos do realismo jurídico aqui estudados surgem como paradigmas para a construção e consolidação do Estado tal como nós atualmente o conhecemos, sendo importante ressaltar a peculiar relevância de Alberto Torres para o desenvolvimento da matriz brasileira.

Com efeito, é possível se concluir que o estudo do realismo jurídico norte-americano e brasileiro pode contribuir para a teoria constitucional atualmente no Brasil cujos desafios demandam, entre outras questões, assentar limites da atuação jurisdicional que não impliquem - e esse parece ser o grande desafio destes novos movimentos contemporâneos -, na configuração arbitrária, injusta e discricionária das relações políticas do direito. Como esclarecem Christian Lynch e José Vicente Mendonça “[a]democracia constitucional de 1988 não nasceu ex novo da constituinte, como Minerva da cabeça de Júpiter. Se a democracia é processo sempre inacabado, a história é seu natural reflexo" (2007, p.1002). Deste modo, o constitucionalismo deve ser considerado no contexto do estudo da história que, por sua riqueza, serve como inequívoca pista que não pode ser desprezada pelo estudioso do direito na busca desta resposta.

Revista de Teorias do Direito e Realismo Jurídico | e-ISSN: 2525-9601 | Porto Alegre | v. 4 | n. 2 | p. $38-53$ | Jul/Dez. 2018 


\section{REFERÊNCIAS BIBLIOGRÁFICAS}

BARROSO, Luís Roberto. Neoconstitucionalismo e Constitucionalização do Direito: o Triunfo Tardio do Direito Constitucional no Brasil. Revista da Escola da Magistratura do Estado do Rio de Janeiro, Rio de Janeiro, nº 33, 2006.

O começo da história. A nova interpretação constitucional e o papel dos princípios no direito brasileiro. In Temas de direito constitucional. Rio de Janeiro: Renovar, 2005.

O direito constitucional e a efetividade de suas normas: limites e possibilidades da constituição brasileira. 8 ed. Rio de Janeiro: Renovar, 2006.

BONAVIDES, Paulo. Curso de direito constitucional. 22 ed. São Paulo: Malheiros, 2008.

CARDOZO, Benjamim N. A natureza do processo judicial: palestras proferidas na Universidade de Yale. São Paulo: Martins Fontes, 2004.

HALIS, Denis de Castro. Teoria do direito e "fabricação de decisões": a contribuição de Benjamin N. Cardozo. Revista Brasileira de Direito Constitucional, Teoria da Constituição. São Paulo, Escola Superior de Direito Constitucional (ESDC), n. 6, pp. 358374, jul/dez 2005.

LYNCH, Christian Edward Cyril. Do direito à política: a gênese da jurisdição constitucional norte-americana. Revista Ciências Sociais. Rio de Janeiro, Gama Filho, vol. 16, 1995.

LYNCH, Christian Edward Cyril; MENDONÇA, José Vicente Santos. Por um história consitucional brasileira: uma crítica pontual à doutrina da efetividade. Revista Direito e Práxis. Rio de Janeiro, vol. 08, nº 2, p. 974-1007, 2007.

SOUZA, Ricardo Luiz de. Nacionalismo e autoritarismo em Alberto Torres. Revista Sociologias, Porto Alegre, n.13, p.302-323, 2005.

RODRIGUES, Lêda Boechat. A corte suprema e o direito constitucional brasileiro. 2 ed., Rio de Janeiro: Civilização Brasileira, 1992.

TORRES, Alberto de Seixas Martins. A organização nacional. Rio de Janeiro: Universidade de Brasília, 1982.

VIANNA, Francisco José Oliveira. Instituições política brasileiras. Brasília: Conselho Editorial do Senado Federal, 1999. 